\title{
Isolation and characterization of organisms in high vaginal swab culture in preterm pregnancy (28-37 week)
}

\author{
Sujata Singh, Sasmita Swain, Lucy Das, Pravat Chandra Das*, Shradhanjali Sahoo
}

Department of Obstetrics and Gynaecology, S.C.B. Medical College and Hospital, Cuttack, Odisha, India

Received: 24 August 2016

Revised: 26 August 2016

Accepted: 21 September 2016

\section{* Correspondence:}

Dr. Pravat Chandra Das,

E-mail: preetadeep15@gmail.com

Copyright: () the author(s), publisher and licensee Medip Academy. This is an open-access article distributed under the terms of the Creative Commons Attribution Non-Commercial License, which permits unrestricted non-commercial use, distribution, and reproduction in any medium, provided the original work is properly cited.

\begin{abstract}
Background: The study was performed to isolate, identify and determine the antibiotic sensitivity profile of the pathogens in the genital tract of preterm pregnant women (28 week- 37 week) gestation to the prevention of preterm delivery, pPROM, chorioamnionitis, neonatal, puerperal and maternal- foetal infections.

Methods: The present perspective study in S. C. B. medical college, Cuttack was conducted in department of Obstetrics and Gynaecology from January 2014 to September 2015 in 100 patients with singleton pregnancy. The cases for study were selected randomly from the patients attending $\mathrm{O}$ and G OPD or admitted to the labour room or antenatal ward. Each of the patients was informed about the type, quality, and consequence of the study as well as their role in this particular participation. Valid consents were obtained from each patient who showed their cooperation. Under available aseptic conditions high vaginal swabs were collected with a commercially available collection and transport system for isolation of pathogens present in the genital tract of preterm pregnant women having gestational age 28 week-37 week. The samples were examined in the Department of Microbiology in S. C. B. medical college, Cuttack.

Results: We have isolated the most common organism in preterm pregnancy is the E. coli amounting $34 \%$ followed by Candidial spp. 21\%. Then comes Enterococci scoring 10\%, then Staphylococci 8\%, Gardenerella vaginalis $7 \%$. Eventually Group B Streptococcus 5\%. However, there is about more number of culture negative cases (no growth $24 \%$ ) according the department of Microbiology of this college. From the above study we got more number of aerobic vaginitis in contrast to bacterial vaginitis. The prevalence of pPROM was associated with E. coli i. e. $30 \%$. Second are Enterococci having 20\%. Candidial spp. Scores 18\%. Gardenerella vaginalis takes 12\%. However, organisms like Staphylococci and GBS comes last with a score of $6 \%$ and $2 \%$ respectively.

Conclusions: As preterm birth is more associated with mother having genital infections. Our study awards the champion cup to the E. coli as it is associated with maximum number of preterm birth cases i.e. $30 \%$. Candidial spp. comes with the number about $21 \%$ causing both symptomatic and asymptomatic infection. Enterococci and Staphylococci almost have same prevalence of preterm birth viz. $12 \%$.
\end{abstract}

Keywords: Aerobic Vaginitis (AV), Bacterial Vaginosis (BV), Group B Streptococcus (GBS), High Vaginal Swab (HVS), Lactobacillus group (LBG), Preterm birth

\section{INTRODUCTION}

Preterm birth is one of the most serious problems in obstetrical care. It is a leading cause of neonatal morbidity and mortality. The causes of spontaneous preterm birth are still elusive. Global literature suggests that the asymptomatic or minimal symptomatic infections are related to premature birth. ${ }^{1}$ The preterm pregnancy is the pregnancy less than 37 week of gestation. In UK it has taken 24-0/7 week of gestation to 36 6/7 week of 
gestation. Lower limit taken in developed country is 20 week of gestation before that it is called as abortion and in developing country it is taken 28 weeks of pregnancy. According to WHO, preterm pregnancy is; pregnancy beyond 20 week of gestation and prior to the completion of 37 weeks.

\section{WHO (Updated November 2015)}

Preterm is defined as babies born alive before 37 weeks of pregnancy are completed. There are sub-categories of preterm birth, based on gestational age: extremely preterm ( $<28$ weeks) very preterm ( 28 to $<32$ weeks), moderate to late preterm (32 to $<37$ weeks). Every year, an estimated 15 million babies are born preterm (before 37 completed weeks of gestation), and this number is rising. Preterm birth complications are the leading cause of death among children under 5 years of age, responsible for nearly 1 million deaths in 2013.Three-quarters of them could be saved with current, cost-effective interventions. Across 184 countries, the rate of preterm birth from $5 \%$ to $18 \%$ of babies born.

A pregnancy is said to be term when it is between 37 weeks and 42 weeks of gestation from $1^{\text {st }}$ day of last menstrual period. Recently ACOG endured a recommendation. That the level term replaced with. Early term-37 0/7 week of gestation through 38 6/7 week of gestation, Full term-39 0/7 week of gestation through 40 $6 / 7$ week of gestation. Late term-41 0/7 week of gestation through $416 / 7$ week of gestation.

The vaginal microflora of healthy asymptomatic woman consists of wide variety of anaerobic and aerobic bacterial genera and species dominated by facultative microaerophilic anaerobic genus lactobacillus. Lactobacilli are the most well-known markers of normal vaginal flora. Donders et al described definition of a type of abnormal vaginal flora that is distinct from bacterial vaginosis: aerobic vaginitis. ${ }^{2}$ When normal bacterial flora is predominately lactobacillary type the abnormal can be disturbed by;

1. Anaerobic overgrowth [bacterial vaginosis (BV)]. $\mathrm{BV}$ is usually polymicrobial infection and organism responsible for infection include: Gardenerella vaginalis, mobilunchus species, mycoplasma hominis, Bacteroides species peptostreptococcus species, fusobacterium species, prevotella

2. Aerobic microorganism Aerobic vaginitis (AV): $E$. coli, Group B streptococcus, S. aureus, Enterococci etc.

3. Mixture of both AV and BV

4. Candidial species.

The normal and abnormal floras are divided into three floral types also called as lactobacillary grades.
1. Normal grade I. Predominantly lactobacillary morphotype.

2. Intermediate grade II. It is two types

- II a- slightly diminished lactobacillary flora with other bacteria

- II b- moderately disturbed lactobacillary flora

3. Grossly abnormal grade III. Complete absence of lactobacilli by other bacterial morpho type viz. cocci, anaerobic coccobacili or small bacillus. In order to diagnose such abnormal Lactobacillary grades the use of the wet mount is preferred the other Gram stain due to its superior accuracy and better correlation with vaginal lactate accepted by most as the best functional test for lactobacillary defense function.

Donders $\mathrm{G}$ et al studied aerobic vaginitis in pregnancy which is one of those diseases that prevalently transmitted by sexual contact and if it is not diagnosed and treated early, during pregnancy can place the health of both mother and fetus at risk as it is associated with preterm birth, pPROM and chorioamnionitis. ${ }^{3}$

Rezeburga et al demonstrated that AV detected both clinically and confirmed by culture at the first prenatal visit before 12 weeks of gestational was related to an increased risk of chorioamnionitis and foetal funisitis. ${ }^{4}$ In another series, neonatal sepsis, most commonly with $S$. aureus, was also a frequent finding in growth restricted foetuses. All these organisms in pregnancy cause Preterm Premature Rupture of membrane (PPROM), preterm labour (PTL), preterm birth and chorioamnionitis, later in neonates causes neonatal sepsis. During preterm pregnancy so many events occur due to various reasons Preterm contraction, preterm labour/ preterm birth, PPROM, chorioamnionitis which later leads to postpartum endometritis.

Bacterial viginosis is believed to be a risk factor for preterm delivery as well as being associated with peripartum complications such as preterm premature rupture of membrane (PPROM), chorioamnionitis which later leads to postpartum endometritis. Bacterial vaginosis is a condition characterized by a change in the microbial ecosystem of the vagina. This is characterized by a decrease in number of lactobacillus and the overgrowth of several anaerobes or facultative bacteria. ${ }^{5}$

\section{METHODS}

The present perspective study of Isolation and Characterisation of The Organisms In High Vaginal Swab Culture In Preterm Pregnancy (28 Week-37 Week) was conducted in department of Obstetrics and Gynaecology of S. C. B. medical college, Cuttack, from January 2014 to September 2015 in 100 patients with singleton pregnancy. The cases for study were selected randomly from the patients attending $\mathrm{O}$ and G OPD or admitted to the labour room or antenatal ward. Each of the patients was informed about the type, quality, and 
consequence of the study as well as their role in this particular participation.

Valid consents were obtained from each patient who showed their cooperation. Under available aseptic conditions high vaginal swabs were collected with a commercially available collection and transport system for isolation of pathogens present in the genital tract of preterm pregnant women having gestational age 28 week37 week.

\section{Inclusion criteria}

1. Singleton pregnancy,

2. Preterm pregnancy (G. A 28 week-37 week),

3. pPROM,

4. Chorioamnionitis,

5. Patients with previous history of preterm birth.

\section{Exclusion criteria}

1. Patient with multiple gestation,

2. Severe anaemia,

3. Diabetes mellitus,

4. Patients consuming alcohol and smoking tobacco,

5. Psychiatric illness precluding informed consent.

On entry into the study all patients were interviewed and detail history, general examination, systemic examination, and obstetrical and abdominal examination were done. Standard speculum examination and vaginal sampling were taken by commercially available high vaginal swab. Appearance of the vulva, vagina and cervix and the characteristics of vaginal fluids were recorded.

\section{Procedure}

This was done with the help of the department of microbiology, S.C.B. medical college, Cuttack. In the laboratory the study of the organism was done in the methods described below. Following laboratory investigations were carried out in all the cases of study group with careful clinical examination.

\section{Microbiological evaluation of vaginal flora}

Specimens were gram stained and cultured in both aerobic and anaerobic methods for identification of pathogens. In Aerobic culture bacteria colonies grown in culture media were identified by their morphology and biochemical reactions like catalase, coagulase, esculin hydrolysis etc. for gram positive organisms. In case of gram negative bacteria; testing for motility, catalase, oxidase, sugar fermentation, oxidation- fermentation, nitrate reduction, citrate utilisation, amino acid decarboxylation, Indole production, urea hydrolysis, $\mathrm{H}_{2} \mathrm{~S}$ production, methyl red and Vagues-Proskaur test etc. were performed for further identification. In anaerobic culture bacterial identification was done by colony morphology, pitting of agar, Gram stained smear from colony, Haemolysis, Catalase test, Growth character in selected and indicator anaerobic media plates and Sensitive to vancomycin $5 \mu \mathrm{g}$, colistine $10 \mu \mathrm{g}$, nitrate and SPS disc. The four Amsel criteria and Nugent's Criteria (Scoring of Gram stain smear)/ Spiegel criteria are the most commonly used diagnostic principles for BV. These are usually regarded as the gold standards.

\section{Antimicrobial susceptibility testing}

It was performed by disc diffusion method of Kirby and Bauer. The test organism was inoculated into protease peptone water, incubated for 4-6 hour. The turbidity was matched with McFarland opacity standard 0.5. A sterile dry cotton swab was dipped into the suspension. Excess inoculums were removed by pressing and rotating the swab firmly against the side of the tube above the level of liquid. The swab was used to streak the surface of the predried single layer human blood agar medium three times rotating the plate through an angle $60^{\circ}$ after each application. The different antibiotic discs used were metronidazole $5 \mu \mathrm{g}$ and $50 \mu \mathrm{g}$, ampicillin $10 \mu \mathrm{g}$, clindamycin $10 \mu \mathrm{g}$ and gentamycin $10 \mu \mathrm{g}$. The plates were incubated at $37^{\circ} \mathrm{C}$ in candle $\mathrm{Jar}$ and the result was interpreted after 48 hours of incubation. Isolate were subcultured on a BBA to ensure an even heavy lawn of growth. The first quadrant was streaked back and forth several times and then other quadrants were streaked to yield isolated colonies. Vancomycin, kanamycin discs were put in first quadrant. For gram negative isolates nitrate disc was added in second quadrant. For gram positive cocci, nitrate and SPS were added in second quadrant. For gram positive rod nitrate was added second quadrant. Antimicrobial agent discs were placed minimum $20 \mathrm{~mm}$ apart. Plates were incubated anaerobically for 48 hours at $37^{\circ} \mathrm{C}$. Zones of inhibition of growth were examined around the disc; susceptible: zone of inhibition of $\geq 10 \mathrm{~mm}$. Resistant: zone of inhibition of $\leq 10 \mathrm{~mm}$.

For Enterococcus spp. amoxicillin clavunilic acid (20/10 $\mu \mathrm{g}$ ), linezolid $30 \mu \mathrm{g}$, vancomycin $30 \mu \mathrm{g}$, ampicillin 10 $\mu \mathrm{g}$, erythromycin $15 \mu \mathrm{g}$. For Staphylococcus aureus amoxicillin clavunilic acid $(20 / 10 \mu \mathrm{g})$, linezolid $30 \mu \mathrm{g}$, vancomycin $30 \mu \mathrm{g}$, cefoxitin $30 \mu \mathrm{g}$ and netilmycin, levofloxacin $5 \mu \mathrm{g}$. For gram negative nonfermenter ceftazidime $30 \mu \mathrm{g}$, piperacillin tazobactam $(100 / 10 \mu \mathrm{g})$, gentamycin $10 \mu \mathrm{g}$ were used. For $E$. coli linezolid $30 \mu \mathrm{g}$, vancomycin $30 \mu \mathrm{g}$, ampicillin $10 \mu \mathrm{g}$, erythromycin $15 \mu \mathrm{g}$, levofloxacin $5 \mu \mathrm{g}$, cefixime $30 \mu \mathrm{g}$. The discs were dispensed onto agar surface aseptically by forceps and firm contact was ensured. A distance of $24 \mathrm{~mm}$ was maintained between the discs. After overnight incubation at $37^{\circ} \mathrm{C}$ the plates were examined for the zone of inhibition. Zone diameters were measured by calipers and strains were reported sensitive or resistant according to the chart supplied. 


\section{Isolation of Candida spp.}

Presence of Candida species was evaluated in wet film and gram stained preparation of vaginal discharge as gram positive budding yeast cells.

\section{RESULTS}

According to Table 1 incidence of $E$. coli is the highest among all the cases i.e. 34\%. Then comes the Candidial species amounting $21 \%$ followed by Enteroccci $10 \%$, Staphylococci 8\%. At the lowest level come the Gardenerella vaginalis 7\% and GBS 5\%. However, in my study about $24 \%$ did not show any growth.

Table 1: Organisms associated with preterm pregnancy.

\begin{tabular}{|ll|l|}
\hline Sr. no. & Organism associated & $\begin{array}{l}\text { Total percentage } \\
\text { found }\end{array}$ \\
\hline 1 & E. coli & $34 \%$ \\
\hline 2 & Enterococci & $10 \%$ \\
\hline 3 & Staphylococci & $8 \%$ \\
\hline 4 & Group B Streptococcus & $5 \%$ \\
\hline 5 & Gardnerella vaginalis & $7 \%$ \\
\hline 6 & Candidial species & $21 \%$ \\
\hline 7 & No growth & $24 \%$ \\
\hline
\end{tabular}

In our study according to Table 2 organism associated with pPROM caused by E. coli is $29.5 \%$ (15/51), followed by Enterococci 19.6\% (10/51), then Candida $17.6 \%$ (9/51), then Gardenerella Vaginalis 11.7\% (6/51). Then comes the Staphylococcus 5.8\% (3/51) and GBS
$1.9 \%$ (1/51). However, in $25.4 \%$ (13/51) no growth occurred.

Table 2: Organism associated With PPROM.

\begin{tabular}{|lll|}
\hline Sr. no. & $\begin{array}{l}\text { Organism associated } \\
\text { with PPROM }\end{array}$ & Percentage \\
\hline 1 & E. Coli & $29.5 \%(15 / 51)$ \\
\hline 2 & Gardenerella Vaginalis & $11.7 \%(6 / 51)$ \\
\hline 3 & Staphylococcus & $5.8 \%(3 / 51)$ \\
\hline 4 & Enterococci & $19.6 \%(10 / 51)$ \\
\hline 5 & Candida & $17.6 \%(9 / 51)$ \\
\hline 6 & Group B Streptococcus & $1.9 \%(1 / 51)$ \\
\hline 7 & No Growth & $25.4 \%(13 / 51)$ \\
\hline
\end{tabular}

According to Table 3 among the organism associated with preterm birth E. coli comes first amounting $30.1 \%$ (19/63) followed by Candida 20.6\% (13/63), Enterococci $12.6 \% \quad(8 / 63)$, Staphylococcus $11.1 \% \quad$ (7/63), Gardenerella Vaginalis 7.9\% (5/63). GBS comes the last amounting $4.7 \%$ (3/63). Eventually in $19.4 \%$ (12/63) did not show any growth.

Table 3: Organisms associated with preterm birth.

\begin{tabular}{|lll|}
\hline Sr. no. & $\begin{array}{l}\text { Organism associated } \\
\text { with preterm birth }\end{array}$ & Percentage \\
\hline 1 & E. Coli & $30.1 \%(19 / 63)$ \\
\hline 2 & Gardenerella Vaginalis & $7.9 \%(5 / 63)$ \\
\hline 3 & Staphylococcus & $11.1 \%(7 / 63)$ \\
\hline 4 & Enterococci & $12.6 \%(8 / 63)$ \\
\hline 5 & Candida & $20.6 \%(13 / 63)$ \\
\hline 6 & Group B Streptococcus & $4.7 \%(3 / 63)$ \\
\hline 7 & No Growth & $19.4 \%(12 / 63)$ \\
\hline
\end{tabular}

Table 4: Antibiotic susceptibility of following organisms.

\begin{tabular}{|lllllll|}
\hline Sr. No. & Antibiotics used & E. Coli & Staph. aureus & Enterococcus & GBS & Gardenerella \\
\hline 1 & Linezolid & $100 \%$ & $100 \%$ & $80 \%$ & N/A & N/A \\
\hline 2 & Vancomycin & $100 \%$ & $100 \%$ & $100 \%$ & N/A & N/A \\
\hline 3 & Nitrofurantoin & $60 \%$ & $60 \%$ & N/A & $40 \%$ & N/A \\
\hline 4 & Cefoperazone and Sulbactam & $80 \%$ & $90 \%$ & N/A & N/A & N/A \\
\hline 5 & Amikacin & $90 \%$ & $80 \%$ & $90 \%$ & N/A & N/A \\
\hline 6 & Amoxicillin and Clavunilic Acid & $30 \%$ & $40 \%$ & $90 \%$ & N/A & N/A \\
\hline 7 & Cefotaxim & $20 \%$ & $90 \%$ & N/A & $50 \%$ & N/A \\
\hline 8 & Ampicillin & N/A & N/A & $0 \%$ & N/A & $90 \%$ \\
\hline 9 & Erythromycin & N/A & N/A & $30 \%$ & N/A & N/A \\
\hline 10 & Gentamycin & N/A & N/A & N/A & $100 \%$ & $80 \%$ \\
\hline 11 & Clindamycin & N/A & N/A & N/A & $80 \%$ & N/A \\
\hline 12 & Metronidazole & N/A & N/A & N/A & N/A & $100 \%$ \\
\hline
\end{tabular}

In Table 4 it is obvious that isolates belong in to $E$. coli is highly sensitive to Linezolid and Vancomycin 100\% (34/34) each. Followed by amikacin 90\% (30/34) then cefoperazone and sulbactam $80 \% \quad(24 / 34)$ and nitrofurantoin $80 \%(20 / 34)$ whereas it is resistance to cefotaxime $80 \%(27 / 34)$ and amoxicillin and clavunate 
$70 \%$ (23/34). This study found that Staphylococcus aureus were more sensitivity to linezolid $100 \%$ (8/8) and vancomycin $100 \%(8 / 8)$ than cefotaxime $90 \% \quad(7 / 8)$ followed by clindamycin $80 \%(6 / 8)$ and nitrofurantoin $60 \%(5 / 8)$. It is mostly resistance to amoxicillin and clavunate $60 \%(5 / 8)$. Enterococcus species is mostly sensitive to vancomycin $100 \%(10 / 10)$ followed by amikacin $90 \%(9 / 10)$ and it is highly resistant to ampicillin $100 \%(10 / 10)$. The isolated organism GBS is highly sensitive to gentamycin $100 \%(5 / 5)$ followed by clindamycin $80 \%(4 / 5)$ than cefotaxime $60 \%$ (3/5). This is highly resistant to nitrofurantoin $60 \%(3 / 5)$. The isolated organism Gardenerella vaginalis highly sensitive to metronidazole $100 \%$ (7/7) followed by ampicillin $90 \%$ $(6 / 7)$ than gentamycin $80 \%(5 / 7)$.

\section{DISCUSSION}

Donders states that causes of AV are: E. coli, enterococci, Staphylococcus spp. and group B of streptococcus. E. coli is cited as one of the most common causes of this vaginitis and sometimes is isolated alone. ${ }^{6}$ Donders also records abnormal status of lactobacilli, that is, their absence, which is a negative factor and enables development of infection, especially in pregnancy. ${ }^{7-11}$ In our study most common organism is the E. Coli amounting $34 \%$ followed by Candidial spp. $21 \%$. Then comes Enterococci scoring 10\%, then Staphylococci 8\%, Gardenerella vaginalis 7\%. Eventually Group B Streptococcus 5\%. However, there is about more number of culture negative cases (no growth $-24 \%$ ). From the above study we got more number of aerobic vaginitis in contrast to bacterial vaginitis.

Vaginal infection, has been associated with increased risks for prematurity and premature rupture of membranes (PROM). ${ }^{12-14}$ In studies by Naeye et al, Das C.R. et al showed that infection was 2-3 times more common in patients with rupture of membranes before 37 weeks of gestation than when foetal membranes ruptured at term. ${ }^{15,16} E$. coli was the commonest organism isolated in the study done by Sharma, Das C.R. et al (44\%), Raunt et al, Agarwal et al. ${ }^{16-19}$ In our study the prevalence of PPROM (N-51) with different organisms was studied with great interest. However, the result came up with most of the cases were associated with E. Coli i.e. $30 \%$. Second virulence association came up with Enterococci scoring 20\%. Candidial spp. scores 18\%. Gardenerella vaginalis takes $12 \%$. However, organisms like Staphylococci and GBS comes last with a score of $6 \%$ and $2 \%$ respectively.

Abnormal vaginal flora in women with the risk for preterm labour and presence of $E$. coli with or without signs of inflammation and increased number of leukocytes in secretion. ${ }^{20,21}$ Pregnant women have a twofold increase in the prevalence of vaginal colonization by Candida species compared with non-pregnant women. ${ }^{22}$ This association is influenced by increased levels of circulating oestrogens and deposition of glycogen and other substrates in the vagina during pregnancy. ${ }^{22}$ There was a higher spontaneous preterm birth rate in women with untreated asymptomatic candidiasis compared to those without candidiasis consistent with Candida colonization as a risk factor for preterm birth. ${ }^{23-25}$ There was a tendency towards a reduction in preterm birth for those women treated with clotrimazole, consistent with that reported by kiss. ${ }^{23}$

As preterm birth $(\mathrm{N}-63)$ is more associated with mothers having genital infections. Our study awards the champion cup to the $E$. coli as it is associated with maximum number of preterm birth cases i.e. $30 \%$. Candidial spp. comes with the number about $21 \%$ causing both symptomatic and asymptomatic infection. Enterococci and Staphylococci almost have same prevalence of preterm birth viz. $12 \%$.

In the antibiogram study isolate belong in to $E$. coli is highly sensitive to Linezolid and Vancomycin $100 \%$ each. Followed by amikacin $90 \%$ then cefoperazone and sulbactam $80 \%$ and nitrofurantoin $80 \%$ whereas it is resistance to cefotaxime $80 \%$ and amoxicillin and clavunate $70 \%$. This study found that Staphylococcus aureus were more sensitivity to linezolid $100 \%$ and vancomycin $100 \%$ than cefotaxime $90 \%$ followed by clindamycin $80 \%$ and nitrofurantoin $60 \%$. It is mostly resistance to amoxicillin and clavunate $60 \%$. Enterococcus species is mostly sensitive to vancomycin $100 \%$ amoxicillin and clavunate is $90 \%$ followed by amikacin $90 \%$ and it is highly resistant to ampicillin $100 \%$. The isolated organism GBS is highly sensitive to gentamycin $100 \%$ followed by clindamycin $80 \%$ than cefotaxime $60 \%$. This is highly resistant to nitrofurantoin $60 \%$. Antimicrobial susceptibility studies of all isolates were performed following Kirby Bauer's disc diffusion technique. The organism Gardenerella vaginalis highly sensitive to metronidazole $100 \%$ followed by ampicillin $90 \%$ than gentamycin $80 \%$.

\section{ACKNOWLEDGEMENTS}

The authors would like to thank professor (Dr.) Lucy Das, HOD, Department of Obstetrics and Gynaecology, S.C.B. Medical College, Cuttack.

\section{Funding: No funding sources Conflict of interest: None declared}

Ethical approval: The study was approved by the Institutional Ethics Committee

\section{REFERENCES}

1. Carey J, Klebanoff M. Is a change in the vaginal flora associated with an increased risk of preterm birth.Am J Obstet Gynecol. 2005;6:1341-7.

2. Donder GG, Vereecken A, Bosmans E, Dekeersmaecker A, Salembier G, Spitz B. Definition of a type of abnormal vaginal flora that is distinct 
from bacterial vaginosis: aerobic vaginitis. BJOG. 2002;109(1):34-43.

3. Donders G, Bellen G, Rezeberga D. Aerobic vaginitis in pregnancy. International Journal of Obstetrics and Gynecology BJOG. 2011:1163-70.

4. Rezeberga D, Lazdane G, Kroica J, Sokolova L, Donders GG. Placental histological inflammation and reproductive tract infections in a low risk pregnant population in Latvia. Acta Obstet Gynecol Scand. 2008;87:360-5.

5. Romero R, Chaiworapongsa $\mathrm{T}$, Kuivaniemi $\mathrm{H}$, Tromp G. Bacterial vaginosis, the inflammatory response and the risk of preterm birth: a role for genetic epidemiology in the prevention of preterm birth. Am J Obstet Gynecol. 2004;190:1509-19.

6. Donders G, Van Kalsteren K, Bellen G, Reybrock R. Predictive value for preterm birth of abnormal vaginal flora, bacterial vaginosis and aerobic vaginitis during the first trimester of pregnancy. BJOG. 2009;116:1315-24.

7. Donders G, Vereecken A, Bosmans E, Dekeersmaecker A, Salembier G, Spitz B. Aerobic vaginitis: Abnormal vaginal flora entity that is distinct from bacterial vaginosis. Gynecology Obstetrics and Reproductive Medicine. 2005:118-29.

8. Donders G, Wet H, Hooft P, Desmyter J. Lactobacilli in Papanicolaou smears, genital infections and pregnancy. Am J Perinatol. 1993;10:358-61.

9. Donders G, Odds A, Vereecken A, Van Bulck B, Londers L, Salembier G. Abnormal vaginal flora in the first trimestr, but not full blown bacterial vaginosis is associated with preterm delivery and low birth weight.Prenat Neonat Med. 2008;3:588-93.

10. Donders G, Vereecken A, Van Bulck B, Cornelis A, Dekeersmaeker A, Klercx P. The ecology of the vaginal flora and first prenatal visit is associated with preterm delivery and low birth weight. The Open Inf Dis J. 2008;2:45-51.

11. Donders G, Van C, Bellen G, Reybrock R, Van Den Bosch T, Riphagen I. Assotiatiom bitween abnormal vaginal flora and cervical lenght as risk factors for preterm birth. Ultrasound Obstet Gynecol. 2010:3537.

12. Eschenbach DA, Gravett MG, Chen KCS, Hoyme UB, Holmes KK. Bacterial vaginosis during pregnancy. An association with prematurity and postpartum complications. 1984;213-222. In P. A. Mardh and D. Taylor-Robinson (Ed.), Bacterial vaginosis. Almqvist and Wiksell, Stockholm. 15a.Gardner, M.J., and D. G. Altman. Statistics with confidence. Br. Med. J. 1989.
13. Gravett M, Hummel GD, Eschenbach DA, Holmes KK. Preterm labor associated with subclinical amniotic Fluid infection and with bacterial vaginosis. Obstet. Gynecol. 1986;67:229-37.

14. Gravett MG, Nelson HP, DeRouen T, Critchlow CC, Eschenbach DD, Holmes KK. Independent association of bacterial vaginosis and Chlamydia trachomatis infection with adverse pregnancy outcome. Jama. Journal of clinical. Microbiology. 1986;256:1899-1903.

15. Naeye RL, Dellinger WS, Blac WA, Fetal and maternal features of antenatal bacterial infection. Am J. Pediatrics. 1978;61:171.

16. Das CR, Pattnaik PL, Sahoo PK. Prevalence of vaginal infection in preterm labour. Antiseptic. 1996;93(4):140-43.

17. Sharma JB, Prevalence of pathogenic Bacteria in Genital tract in preterm labour. J. Obstet and Gynecol of India. 1989;229.

18. Raunt MD, Dora H. Premature rupture of membrane -A clinical and bacteriological study. J of Obst Gyn. 1988;38(1-6);184-7.

19. Agarwal SK, Rathi AK, Awasthi A, Khan AM. J Of Obst Gyn of India. 1979:40-44.

20. Carey J, Klebanoff M. Is a change in the vaginal flora associated with an increased risk of preterm birth.Am J Obstet Gynecol. 2005;6:1341-7.

21. Hagberg H, Mallard C, Jacobsson B. Role of cytokines in preterm labour and brain injury. BJOG. 2005:112-116.

22. Sobel JD. Vulvovaginal candidosis. Lancet. 2007;369(9577):1961-71.

23. Kiss H, Petricevic L, Husslein P. Prospective randomised controlled trial of an infection screening programme to reduce the rate of preterm delivery. BMJ. 2004;329(7462):371.

24. Chaim W, Mazor M, Wiznitzer A. The prevalence and clinical significance of intraamniotic infection with Candida species in women with preterm labor. Arch Gynecol Obstet. 1992;251(1):9-15.

25. Figueroa R, Garry D, Elimian A, Patel K, Sehgal PB, Tejani N. Evaluation of amniotic fluid cytokines in preterm labor and intact membranes. J Matern Fetal Neonatal Med. 2005;18(4):241-7.

Cite this article as: Singh S, Swain S, Das L, Das $\mathrm{PC}$, Sahoo S. Isolation and characterization of organisms in high vaginal swab culture in preterm pregnancy (28-37 week). Int J Reprod Contracept Obstet Gynecol 2016;5:3853-8. 